\title{
Using a life course perspective to understand early labor market exits for people in their late 50s living in the UK
}

\author{
By Jon Swain*, JD Carpentieri*, Samantha Parsons* $\mathcal{E}$ Alissa \\ GOODMAN*
}

\begin{abstract}
This paper explores the reasons why people exit the UK labor market early and some of the barriers working against them returning. The specific focus is a qualitative exploration of three out of work individuals, approaching the age of 60 , each of whom had experienced poverty and periods of worklessness during their lifetime. The fieldwork took place in 2016 and was part of a wider mixed methods study about retirement, which used data from the 1958 birth cohort study. Researchers used narrative interviews to uncover the lived experiences and realities of these three people's lives, and applied a life course perspective to understand how the accumulation of advantages and disadvantages during their lives shapes their attitudes and expectations. The data also show the effects of money, health, and previous employment on their decision making, and how structures such as social class, gender, and poverty are represented in and through the stories they tell.
\end{abstract}

Keywords: labor market exits, barriers, retirement, life course, narrative, agency.

*Jon Swain, JD Carpentieri, Samantha Parsons \& Alissa Goodman, Institute of Education, Department of Education, Practice and Society, University College London, London, UK. 
International Journal of Ageing and Later Life

\section{Introduction: Context and Background Literature}

Leaving the labor market is often a complex process and has profound consequences for the individuals involved. This decision can be made either voluntary or involuntary but sometimes the act can happen almost subconsciously as a gradual realization begins to dawn on a person that they are unlikely to work again.

With the impending retirement of the late baby boomer generation, improved health outcomes leading to generally increasing life expectancy, declining birth rates, transformations in work resulting from globalization, and continuing budget restrictions due to the financial crisis of 2008, the current policy in many industrialized countries has moved away from promoting early retirement to an emphasis on extending employment (Fleischmann et al. 2013), and creating more "active ageing" (Formosa 2014; Hamblin 2010) and "fuller working lives" (Foster 2018; Hofaecker et al. 2019; Hovbrandt et al. 2019; Phillipson et al. 2017). Although Phillipson et al. (2017) maintain that many of the policy reforms in the UK from the last 15 years or so have lacked coordination and coherence, a central pillar of the government policy has been driven by the need to mitigate concerns in the business community and avert a feared pension catastrophe that has the potential to threaten the viability and sustainability of the welfare state itself (Brown \& Vickerstaff 2011; Esping-Andersen 1996). For these reasons, studying people's early exits from the labor market and investigating aspects of working life that motivate older workers to keep working are highly relevant and urgent (e.g. Ekerdt 2009; Hovbrandt et al. 2019), and have become a central concern to policy makers, pension program calculators, and researchers working in the fields of gerontology, associated health studies and labor economics. Of course, another way of looking at these attempts to prolong working lives is that governments of all political persuasions need to try to prevent, or at least make it more difficult, for people to leave employment prematurely. Many countries have already raised pension ages or have legislated increases for the future (Organization for Economic Co-operation and Development 2017), and in the UK it is currently 66 years, and by 2028 it is planned to reach 67 .

In the UK, as well as in Europe (e.g. see Komp et al. [2010], there has actually been a notable increase in the number of people in employment, aged 50 years and over, during the last two decades: at the time of the 
research reported in this paper, in 2016, the employment rate for the people aged 50-64 was $71 \%$, which was 13 percentage points higher than the rate 20 years ago (DWP [Department for Work and Pensions] 2017). In terms of when people leave employment, there has also been an upward trend in the average ages, although this has only recently returned to the rate last seen in the 1970s (DWP 2017). At the beginning of the century, men left employment at an average age of 63 and women at 61, but by 2016, this had risen to an average age of 65 and 64, respectively (DWP 2017: 14). However, Phillipson et al. (2017) maintain that, although retention rates of older workers in their jobs may have improved, prospects for recruitment to new jobs for this age group continue to remain poor. Moreover, over half of the men and women were not in work in the year before reaching State Pension Age (SPA) (DWP 2017), and one in four men and one in three women had not worked for 5 years or more before SPA; there were also almost 1 million individuals, aged 50-64 years old, who were not in employment but say that they are willing to, or would like to, work (DWP 2017: 7).

In the majority of the industrialized countries, the traditional threephase life course chronology of education, work, and retirement (which is particularly applicable to men) has been slowly transformed (Evans, Schoon \& Weale 2013), and exit patterns from employment to retirement have become increasingly heterogeneous and fragmented (Hallerod et al. 2013). We maintain that the reasons why individuals leave paid employment are numerous and complex, and frequently overlap. Whereas rational choice models that underpin many policy assumptions presume that people will carry on working if they cannot afford to retire (e.g. Beehr 2014; Brown \& Vickerstaff 2011; Quinn et al. 1990), contend that this is only a small part of the story and that the expanding literature on this area has settled around five main influential, and typically interdependent, factors or variables: in addition to financial status, there are health, decisions of partners and/or close family members, caring commitments and job satisfaction. However, as Ragin (1999) and Brown and Vickerstaff (2011) point out, there is a "causal complexity" (531) in the interaction of these variables, where seemingly similar circumstances amongst people (such as poor health) can lead to very differentiated outcomes. For example, Brown and Vickerstaff (2011) argue that structural variables (e.g. of 
International Journal of Ageing and Later Life

social class) do not necessarily need to have such an overwhelming impact on people's lives. For example, while there may be an association between social class and levels of social and cultural capital and empowerment, some people will be able to have a greater level of agency than others because they are able to develop coping skills and strategies, perhaps through social networks and other support systems such as from family and friends. Greater economic resources may also enable agency to become more affordable and lead to greater levels of empowerment.

There is relatively little research on how physical challenges at work influence labor market transitions of older workers, especially near retirement ages, but using US data from the Health and Retirement Study from 1992 to 2008, McLaughlin and Neumark (2018) suggest that recent policy changes intended to delay retirements of older workers and extend their work lives can run up against barriers owing to rising physical challenges of work as people age. Hazardous and adverse physical working conditions are concentrated in some male manual occupations, which are also associated with more unhealthy lifestyles (e.g. smoking, diet quality, and alcohol consumption). They argue that, although some older male workers with physically demanding jobs are able to mitigate the challenges of their jobs - either at new jobs or with the same employer - many are unable to accommodate the demands.

Some of the other main barriers that limit late employment prospects, and the likelihood of working up to SPA, are poor qualifications and lack of skills training (Lain \& Vickerstaff 2015). These are particularly prevalent amongst the poorest sections of society (Radl 2013) and are a notably acute problem when these individuals are competing in the labor market against younger people who have more qualifications and up-to-date skills, and are more confident to attend training. Disproportionate numbers of them are working, or will have worked, in "Lopaq" occupations: "typically low paid, part-time and requiring few qualifications" (Phillipson et al. 2017: 7), and echoing the point made by Lain and Vickerstaff earlier, these jobs are also likely to provide fewer prospects for in-house training or progression in, for example, new technologies.

Recently, academic researchers from Europe, the UK, and the US have drawn on a number of large longitudinal data bases and have used quantitative surveys to investigate questions about early exits. These have highlighted a number of reoccurring themes, such as workers' motivations for 
Using a Life Course Perspective

early exits (Du Prel et al. 2019); the effects of poor physical health and wellbeing (Ebbinghaus \& Radl 2015); physical limitations on early exits (Leinonen et al. 2018; McLaughlin \& Neumark 2018; Stafford et al. 2017); and mental health, in the form of anxiety and depression, (particularly for women) (Rudolph \& Eato 2016); and low cognitive performance in the 50s as an indication of early exits (Stafford et al. 2017).

Brown and Vickerstaff (2011) argue that some of this previous research about early exits, that has used quantitative surveys, can treat some factors (e.g. health) as being "straightforward," "objective," or "independent" variables and cautions against overlooking more subjective experiences and expectations. Qualitative research (e.g. Smeaton et al. 2017) allows researchers to explore the nuances and subtleties of the decisions individuals take - including emotional factors - and their expectations about whether to either continue to work, look for work, give up work for a short period, or retire completely. Brown and Vickerstaff (2011) argue that policy debates around extending working lives and deferring their retirement will be much more successful if they are able to recognize how individuals construct narratives about their situations, including their reasons for exiting the labor market and expectations formed from their previous experiences over the life course.

Following the injunction of these researchers, this paper explores the reasons why, rather than when, people have exited the labor market in the $\mathrm{UK}$, and the barriers working against them returning. The specific focus is a qualitative, in-depth exploration of three older workers, approaching the age of 60 . The researchers use narrative methods to uncover the lived experiences and lived realities of these three people's lives, and also apply a life course perspective (Elder \& Giele 2009; Elder et al. 2003) to analyze and understand how the accumulation of advantages and disadvantages during the life course, and the contribution of various experiences, affects, and shapes attitudes, and the expectations and decisions that these three have made and are making.

\section{Methodology}

The fieldwork for this paper was part of a wider mixed methods research study about retirement (Carpentieri et al. 2017), which was funded by the Joseph Rowntree Foundation. The research used data from the 1958 birth 
cohort study (also known as the National Child Development Study or NCDS). Following the lives of over 17,000 people born in a single week, the most recent quantitative sweep was in 2013, with 9,137 individuals aged 55, and included specific questions about cohort members' attitudes toward retirement and, for those still in work, their expectations of when they might leave the labor market.

The original mixed methods study (Carpentieri et al. 2017) was quantitatively based on cohort members who had answered these questions about retirement, and, qualitatively, on interviews with a subset of 36 of these individuals, who aged 58 at the time of the fieldwork, in 2016. One of the main themes investigated in the quantitative research was the effect of poverty on retirement attitudes and expectations, and a subset of 36 participants was purposively chosen for qualitative research because they had reported experiencing low pay, and/or poverty, at the ages of 50 and 55. Being poor at any given age was defined as being in the bottom $20 \%$ of the income distribution within the cohort (rather than being referenced against a national poverty line). The sample was geographically divided: 19 interviewees lived in the South East of England, including London, and 17 lived in the North. The gender split was 50-50. While 25 of the 36 were further purposively selected because they were still in work (mainly in relatively low-paid and low-skilled jobs and categorized as the working poor), the other eleven were chosen because they had exited the labor market and out of paid employment. It is from this eleven that we have decided to focus on three individuals in order to carry out greater in-depth analysis of their narratives than would have been possible with eleven. The three cases were generated inductively from the empirical data and represent a particular, or distinct, type that represents stories from the sample of eleven.

We are aware that this approach can never fully capture the heterogeneity of the qualitative interviewees' responses from the sample of eleven, yet alone the stories of those from the thousands in the wider quantitative survey who were out of work, and for instance, no one from the eleven had been made redundant from their workplace. Nevertheless, we believe that each of the three individuals represents a distinct and particular story that is typical and commonly found amongst people from similar economic backgrounds and who are unemployed as they approach the age of 60 . While we are not claiming them to be representative of a possible 
wider population, we are regarding the three stories as being "telling" cases (Candappa 2017), which allow us to draw out concepts and theories from the cases. They can also be viewed as "revelatory" cases (see Liebow 1967), where researchers are able to gain access into the daily lives of relatively poor people approaching 60 and provide important insights into why they have left their employment, and the barriers preventing their return, so stimulating further policy action, and allowing researchers to develop hypotheses that can potentially be tested using quantitative data sets, such as those of the NCDS.

Although the cases vary in that they consist of one woman and two men, two from the north and one from the south of England, all three individuals were white British, the same age of 58, were living alone in a rented accommodation, had poor to moderate physical health concerns, and all had experienced poverty and periods of worklessness at some point in their lives. One woman (Anne) wanted to work but was unable to find a job; one man (Mark) did not want to work and was content to continue living on meager financial resources without seeking paid employment; another man (Lewis) had retired because the work on offer was so personally unfulfilling and had no plans to reenter the labor market. If we were to try and further categorize these three people, we would say that the first individual was a person who is desperate to be employed and is looking for work; the second can get by living without being employed and is not looking for work; while the third has retired and will not work again. However, these typologies also reveal a series of smaller, or micro, stories, which enable us to highlight and discuss particular issues. For instance, the age discrimination that Anne faced as she realized that many firms and organizations prefer to employ younger people, who they can pay less, or the difficulties she encountered because she could only offer to work for a limited number of hours due to her child-caring responsibilities.

Three experienced researchers interviewed the participants, face to face, in their own homes. The interviews not only were semi-structured, which provided a topical framework, but also gave the interviewers the flexibility to probe on certain issues with more open and follow-up questions. This meant that, although the interviews were relatively structured, in the sense that there were a designated series of main questions that every interviewee was asked to respond to, the questions were not necessarily asked in the same order, and people were also given the freedom 
International Journal of Ageing and Later Life

to talk about, and elaborate on, other connected areas if they wanted to. Two interview schedules were developed: one for interviewees who were in paid employment, and one for the eleven who had existed the market. The interview schedule for the eleven was divided into eight areas of enquiry: in addition to asking questions about why they were not in the labor market, questions also collected demographic information and data on their general health, history of employment, their feelings about growing older, leisure interests, caring responsibilities, and their financial situation. The average interview time was $90 \mathrm{~min}$, and all data were all digitally recorded and transcribed. The participants have been given pseudonyms, and any identifying features of their stories have been suitably anonymized.

We utilized narrative analysis (Riessman 2004) to identify and investigate the potential significance of stories that the interviewees told us. Cohort studies, of course, inherently contain some narrative properties: they enable researchers to follow individuals' lives through time and allow for the estimation of models that focus on how earlier life experiences and environments may impact on later outcomes (Elliott 2005) - for example, the ways in which the experience of poverty over the life course may influence why they have chosen, or been forced, to exit the labor market early. The most concise definition of narrative is a story with a beginning, a middle, and an end; however, a successful narrative is more than just the chronicle of events that is found in the data from surveys such as the NCDS, and Labov and Waletzky (1967) have argued that a defining feature of a typical narrative is that the teller does not just list events or actions; he or she interprets them. Narratives can thus be seen as a powerful and useful tool for exploring the meanings of events and experiences from an individual's perspective, and for improving researchers' and policymakers' understanding of individuals' attitudes, plans, and expectations regarding themes such as why particular people are outside the labor market in their late 50s.

In order to make sense of these interview data, we used a type of thematic analysis called a hybrid approach (Swain 2018), which incorporates the two main contrasting philosophical methods of reasoning: a top-down, deductive, theoretical process and a bottom-up, inductive, data-driven process. The former produces a set of a priori (or pre-empirical) codes that come from the research aims and questions, and individual 
interview questions, whereas the latter approach results in a series of a posteriori (post-empirical) codes that derived from an examination of data generated.

In other words, many of the a priori codes were known to researchers before the first interview began. For example, living accommodation, health, employment history, financial resources, and reasons for early exits would already all be listed because interviewers were tasked with asking specific questions about these areas or themes.

On the other hand, it was much harder to foresee the a-posteriori codes that began to emerge as we read through the interviews transcripts on the completion of the fieldwork. Some of these codes that were created included death of partner, lack of training, contentment with life, volunteering, and so on.

\section{Theoretical Perspective}

\section{The Life Course}

The theoretical approach we use in this paper is the life course perspective. Although there has recently been an increasing emphasis on using mixed methods, the majority of similar studies using life course theories (e.g. about a stage of retirement) have adopted quantitative methodologies. Despite there being no unified theory of the life course, it contains four common perspectives or principal themes (Elder 1994; Heinz et al. 2009; Settersten 2003): (i) individuals' lives follow trajectories that are situated in a specific historical time and place; (ii) the meanings and consequences of their lives are affected by the timing and nature of transitions and key events; (iii) lives are socially connected to, and interdependent with, other key people; and (iv) people have a degree of agency to make choices and form plans, although they live and operate within structural constraints.

The life course contains a series of long-term identifiable pathways called trajectories, such as education, employment, and family, and short-term transitions, which occur within trajectories and are biographical milestones that produce changes in status, ranging from, for example, leaving school, beginning work, to retiring. One of the principal concepts of the life course is that the later years of a person's life cannot be fully understood without knowledge of the prior stages (Elder 1994): for example, the repercussions 
International Journal of Ageing and Later Life

of choices made in early adulthood can be seen in the forms of economic resources people have accumulated, the skills and the attributes they have assimilated, and the activities they pursue in their later years.

Similar to transitions are key events, which can also become turning points (Verd \& López 2011). These are more akin to "biographical disruptions" (Verd \& López 2011) or "discontinuities", (Settersten 2003) and can lead to moments of significant change. However, rather than being seen as single events, they need to be understood more as processes, and they can be positive (such as finding a new job or a partner) or negative (such as losing a job, a divorce, or experiencing a serious health issue). The extent to which a turning point leads to a loss of personal control is contingent on the amount of preparation a person has made, as well as the nature and severity of the change (Elder 1994).

Because lives are socially connected and lived interdependently, these events will often involve changes in other people as well, and so, along with key events, there may also be key people who can have a profound influence on individuals' lives. These include, not only family members and partners, but also special friends, employers, teachers, and so on, and, for some people, figures in the media. Key people and key events will also often overlap and can be difficult to disentangle, and they will also often be connected to linked lives: for example, a divorce will involve a key person (their partner) in a linked life, which may also then take on the status of a key event.

As we have mentioned earlier, one of the central principles of the life course has been the agentic concept of individuals being able to shape, or have a major influence on, their own trajectory (Elder \& Giele 2009). Although personal agency can be difficult to both define and/or identify, we are using the term to mean the capability and degree to which individuals are able to act or "exercise control" (Bandura 2001:11) over events and situations. Any understanding of human agency begins with a recognition that the life course is affected by multiple influences such as macroeconomic conditions, institutional structures (e.g. social class) as well as acquired attributes, dispositions, and individual resources such as motivations and aspirations (Evans \& Biasin 2017). The degree of agency an individual is able to invoke is also affected by their access to other resources such as financial and social capital, and this means that the implications, or consequences, of a key event/turning point (cited earlier) will be different for different individuals. 
We also recognize that the decisions people make are affected by the past, present, and future (Emirbayer \& Mische 1998; Heinz et al. 2009). This means that there is a great heterogeneity in the amount of choice and agency that individuals have in their decision to exit the labor market and how permanent this state remains. The structural factors that are likely to be particularly influential are socio-economic status (Komp et al. 2010), including financial status and poverty (Banks et al. 2005; Scales \& Scase 2000) where, for example, those on lower incomes (and who are likely to have lower pensions and savings) are much more likely to be forced to continue working for financial reasons and not be able to exit the labor market early, at least voluntarily. Gender is another factor, and the differentiated experiences of men and women approaching retirement have been increasingly understood (Vickerstaff \& Cox 2005). Women often confront their retirement years with different amounts of economic, social, emotional, and physical capital than men (Moen 1996), and changing family responsibilities means that they commonly experience less stable employment histories; more women move in and out of the labor market, often in part-time jobs, and consequently, they can therefore expect a lower income from a state or work-based pension. Another important factor is health (Banks \& Smith 2012), which is further complicated because the health of a spouse, or of a significant other, may also have a dramatic effect (Carpentieri \& Elliott 2014). These structures mean that the three individuals in this paper may have a limited scope for agency.

\section{Three Case Studies}

We begin this section by introducing the three interviewees as a series of vignettes.

- A woman who liked, and wanted, to work but was, for a variety of reasons, unable to find a job - an involuntary exit: wants to work

- A man who did not want to work and was content to continue living without seeking paid employment - a voluntary exit: does not want to work

- A man who has retired because he finds the work on offer unfulfilling and has no plans to re-enter the labor market - a voluntary exit: has retired 
International Journal of Ageing and Later Life

Anne: Desperate to Be Employed and Is Looking for Work

Anne had been living alone for the last 5 years in rented accommodation in a small town in the north of England. Although her mental health was sound, she had suffered a number of physical health problems over the past few years: "I've got bad knees, I've got bad hips, just everything," and at the time of the interview, she was waiting for an operation on her back. Her husband died 10 years ago and she found it very difficult to cope. "I didn't want to carry on - I wanted to give up life." She could not bear to live in the same house and so decided to sell it, give the proceeds to her two grown-up children, and move a few miles to the town where her siblings lived, and in which she now resides. She spends a lot of her week looking after her two granddaughters, including taking them to and from school.

Anne left school at the age of 16 with relatively poor qualifications. She worked for nearly 20 years as a chef, but after leaving because of her back problem, she was employed in a variety of roles by a major supermarket. She has a strong work orientation, and maintained that she has "loved every job I've had because I just like to work," pointing especially to the routine and social aspect of employment: "I like talking to people I totally miss it." Her last part-time job on the supermarket checkout had been organized around looking after her grandchildren before she was unable to continue due to ill-health.

After being briefly in the receipt of disability benefits, she was reassessed as being physically capable of work for less physically demanding work. In order to continue receiving benefits, Anne was required by UK law to actively and regularly seek paid employment, spending, on average, $20 \mathrm{~h}$ a week on a computer looking for a work.

She found her dependence on government assistance to be:

Upsetting to think that you've come to this, you know, in your life. You don't really want to be on the dole [government funded unemployment benefit], you don't want to be unemployed. [But] sometimes your body puts you through these things and it's annoying and upsetting. I could still be at work, if it wasn't for my health.

She did not regard herself as being retired, or near retirement: "I've still got eight years left!" Although she would lose out financially by working, because the majority of her rent would not be paid by government benefits, she was currently looking to get back into part-time work. However, 
her lack of qualifications or up-to-date training, her poor health, and the scarcity of locally available work were making this extremely difficult. Sometimes, she recalled, there "could be 200 people going for one job." She had had some interviews but confided that she just could not get the hang of "these modern application tests": "I'm too old now." What she wanted, she affirmed, was to find a job, work to retirement age, and then become "an honest retirer instead of being an unemployed retirer."

Apart from her benefits, she also received a small, monthly pension from her deceased husband's pension scheme. Money was tight but she appeared to be able to get by, although she could not afford to go swimming or have an evening out with her friends in her old town because there were no evening buses and she could not afford a taxi back. Her main worries were her health, which she felt was going to get worse: "as I get older I'll struggle more, I think."

Mark: Can Get by Living without Being Employed and Does Not Want to Work

Mark was living alone in a small northern town and, at the time of the interview, had been out of work for about 4 years. He was not in good physical health and also had mobility issues:

I've got what they call rolling knee, so I've had problems with my mobility, especially carrying things. So like even going upstairs and stuff and things like that I'm in pain all the time. I take painkillers four times a day for it, and I'll be on them the rest of my life.

He was worried about his health: his brother died of a heart attack in his early 50s, and both his parents died of a cardiovascular disease in their early 60s. Mark also has memory problems and, for example, has trouble in remembering people's names or the ages of his grown-up children. He says he finds learning difficult, particularly when it concerns technology.

In many ways, Mark appears to have had a difficult, and sometimes, unhappy life. He has had two marriages, from which he has had five children, although one died at a comparatively young age. He only sees one of his children, but not on a regular basis, and he has no close friends or relatives.

He left school at 16, with poor qualifications, to join the army and has also worked in the steel industry, in a factory, and as a security guard. 
International Journal of Ageing and Later Life

Most of these jobs have been physically demanding and, for most of the time, he has not enjoyed them. He said he left his last job because he could not afford to renew his security license. He has had two spells of lengthy unemployment, which has meant that over the course of his adult life he has been out of work almost as long as he has been in work.

One might think that he may be depressed, but he expressed that he was very satisfied with life in general, and was feeling optimistic about the future. Until recently, he lived with his second wife and one of his daughters, but he now lives alone. He did not get along with his wife, who, he felt, dominated him, which included her looking after his finances, but he now feels in control of his life. He has no caring obligations for older or younger people.

He was receiving a modest income, but his rent and most of his utility bills were being paid from his Jobseeker's Allowance (a government benefit). He has a small pension from his job as a steel worker, which he took at 50, and from which he is able to save a few pounds most months. He confided that he never wanted to own a property as this would come with too much responsibility. He has low aspirations and expectations and is satisfied with a few material belongings. He does not have a TV, rarely drinks alcohol, and spends very little money on food. He has never had much money anyway and so claims he does not miss it.

He was currently volunteering 5 days a week in a local charity shop, which has given him social access to a group of working people and a sense of purpose and routine. He has also gained confidence from feeling needed by the shop. Mark says that he does not regard himself as being retired, declaring: "I'm definitely not retired. I would say I'm just not working." He says - perhaps rather typically of many others - that he does not enjoy taking "the benefit payments"; he is interested in working again, and would like to work on a full-time basis, although, due to his poor health, he recognizes that his employment options are restricted.

Lewis: Retired and Will Not Work Again

Lewis was living alone in a small rented flat in a town in the south of England. He was friendly but admitted to being "a loner and always have been" and enjoys living by himself: the thing, he says, that means the most to him is "peace and quiet." He has no real friends but is very self-contained, and ensures that his life has a built-in structure that includes daily 
walks and coffees, and regular visits to the library. Although his mental health is fine, he developed diabetes in his 30 s and anticipates that his health will increasingly deteriorate.

$\mathrm{He}$ is the youngest of four siblings; he has never had a cohabiting partner and has no children. He left school at 17 with some basic qualifications and his main career has been in the civil service at a junior level, where he worked for almost 30 years. Around the turn of the century, he was working in London, but he opted to take a career break to move to, and look after, his mother, who had dementia, near the town where he now lives. ,When she died 2 years later, he decided to give up his job and stay in the area permanently. He had also bought a flat near the Olympic site in London but sold it a year or so before the decision was made to award the Olympic games to London. He regards this as his biggest financial regret as he could have acquired a lot more money if he had waited: "Having your own flat in east London or that part of London at that time would have just been like winning the Lottery, quite frankly."

Subsequently, he found it difficult to gain employment in professional and/or stimulating jobs, blaming the fact that he was regarded as being too old and "the wrong gender," and he ended up taking a series of low-skilled, low-paid jobs in the private sector, such as in call centers. After spending so long working in the public sector, he also found it difficult to adjust to working for private companies: "There's something the private sector wants from you which with me isn't for sale." He also recalled that "I just felt unwanted," working in jobs he did not believe in. After becoming increasingly disillusioned, he decided to take his civil service pension 3 years early and retired in 2015, aged 57. He was not receiving any state benefits and has no intention of working again.

His main worry is his physical health, and also, to a lesser degree, his finances, although he says he has enough money to "get by" on the modest lifestyle he lives. "I'm not rich, I'm just not poor... I just cut my cloth, you know... I don't drive, I don't smoke, I don't have any dependents, I don't have a great social life... I'm very low maintenance."

Summary of the Three Case Studies

Before we present our analytical discussion, we begin by providing a descriptive summary of the three interviewees' background circumstances, attitudes, and personal feelings in Table 1. 
International Journal of Ageing and Later Life

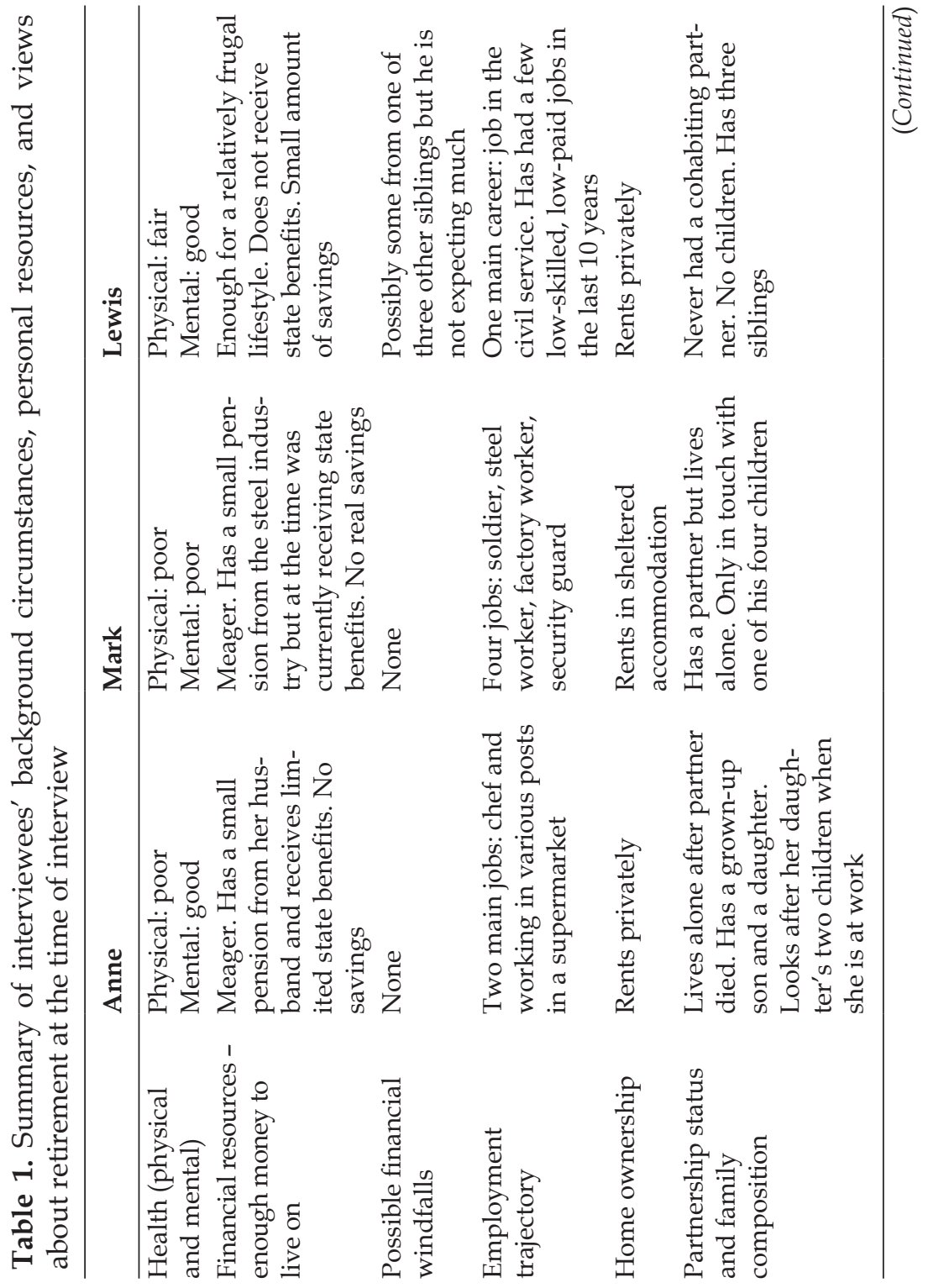


Using a Life Course Perspective

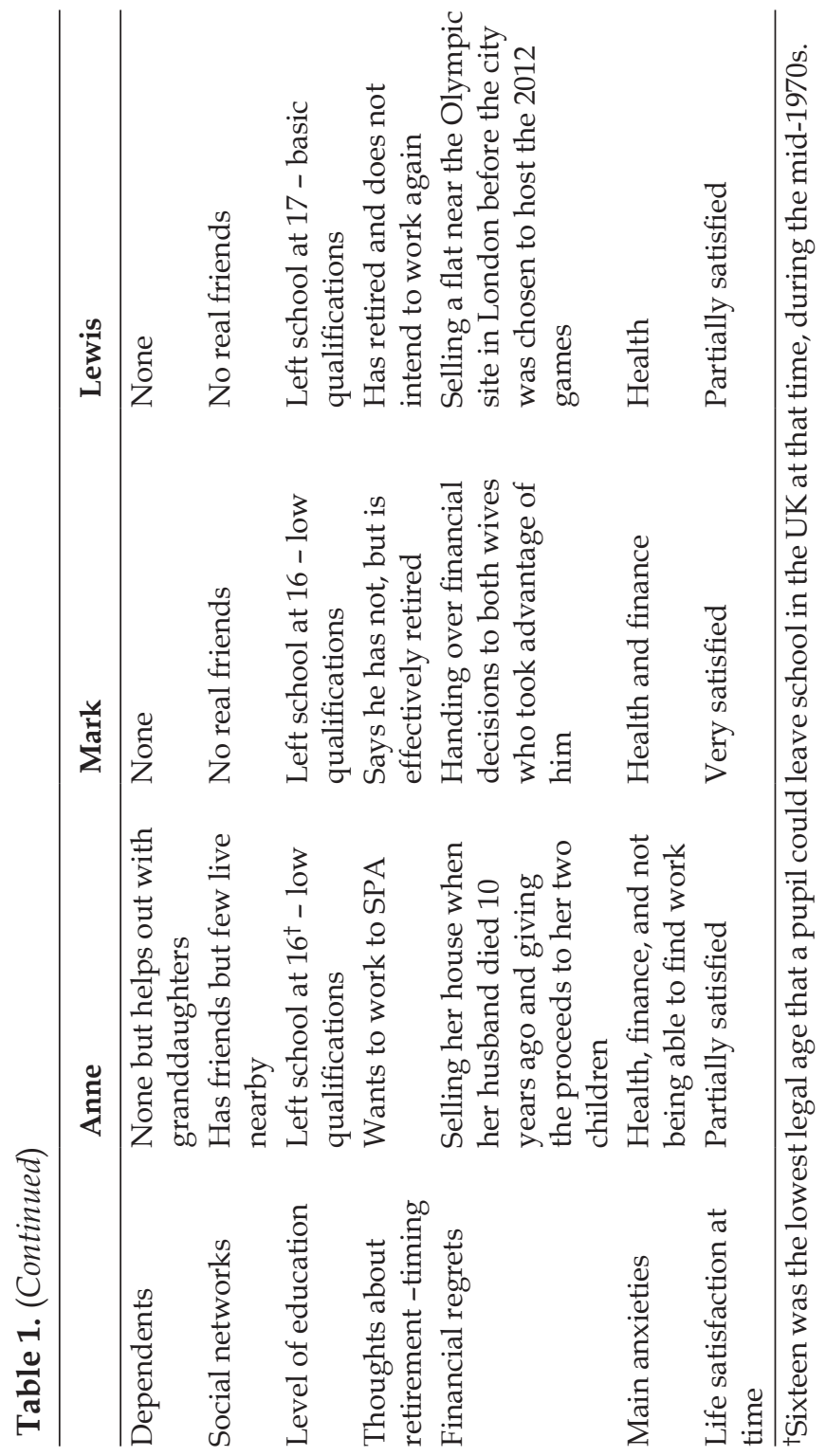


International Journal of Ageing and Later Life

\section{Analysis and Discussion}

Our analysis shows how we apply some of the main paradigmatic features of the life course, which we set out earlier, in order to develop our understandings about how and why particular individuals have exited from the labor market, 8 years before SPA. Although we regard their exit from the market as being a transition, as so much data about transitions are either missing or too speculative, the headings we use to organize our discussion are (employment) trajectories, turning points, key people and linked lives, and agency.

\section{(Working) Trajectories}

In this section, we focus on the interviewees' working trajectories, which have been a central part of, and helped to structure and organize, their lives (Henretta 2003). Two interviewees left school at 16 and their lack of qualifications has meant that they have had a limited range of career options, which continues to have repercussions in their later lives and future years. Both have worked in jobs which have been relatively low-skilled and low-paid: Anne has had two main jobs, while Mark has had four main jobs, three of which have been physically demanding and have taken a toll on his physical health. Although Lewis only stayed on at school for another year, his higher range of qualifications gave him more choices of career and he has spent the majority of his working life in a professional job, which has given him a stability. The series of uninteresting, low-paid jobs that he worked in after leaving the civil service were a factor in his decision to retire early.

The history and trajectory of these three adults' working lives has had a major effect on their financial resources, which, in turn, has affected the type of life they are leading and would wish to lead, the accommodation they live in, and on their aspirations and expectations for the future. Lewis has the greatest amount of financial capital, which he has accrued by working for a considerable part of his working life in the state sector: this has provided him with a work-based pension, which, as we will see later, gives him more options or agency to either return to work or decide to retire completely, which he has done. All three are relatively poor and none own their own property: Anne and Mark receive state benefits, 
which pay for their housing, while Lewis' rent is covered by the income he earns from his work-based pension. Although Mark also receives a work-based pension from the state-run steel industry, the small number of years he spent working means that the amount is negligible.

\section{Key Events}

We can see that all three have experienced key events and turning points that have disrupted their lives and have had profound consequences in the succeeding years. Poor health has affected each of them and continues to do so: Anne's physical disability has been a contributory factor in losing her job, first as a chef, and also in her struggle to reenter the labor market, while Mark's knee problems have also severely restricted his employment options. For Lewis, the discovery that he was diabetic in his 30s has resulted in a loss of confidence about his health, which he expects to slowly and inevitably deteriorate and has possibly affected any ideas of long-term planning for the future.

As researchers, we acknowledge that it can be difficult to judge when a particular event is deemed to be "key," and sometimes the consequences or repercussions of an event (e.g. the death of a close associate) may not become known for some time in the future. Researcher's interpretations invariably involve a lot of speculation, and a researcher's and participant's idea of whether an event is a turning point may not always be the same. Moreover, as we will see later, some of these turning points can have positive as well as negative consequences and repercussions over a longer time span. It would seem, though, that the death of Anne's husband around 10 years ago and the loss of her job at the supermarket due to ill health have been the key events. The earlier details of Mark's life are rather unclear, and we do not know enough about his first divorce or the death of one of his children, or brother, to know their effects. It is too early to tell whether leaving his wife recently and setting up home on his own will turn out to be a turning point but it seems likely it will, and it has certainly led to higher levels of contentment. For Lewis, the ill health of his mother meant that he gave up his job as a civil servant and he moved to be near her so he could look her after; while his decision to sell the 
International Journal of Ageing and Later Life

property he owned in London near the Olympic site, just before London was awarded the Olympic games, means that he is less financially secure.

\section{Key People and Linked Lives}

As we have seen earlier, many of these events have involved relationships with key people, although it can be difficult to tell whether an individual can, or should, be judged as being a key influencer in a person's life, and, like turning points, we will often need time and the benefit of hindsight. Key people are also connected to the theme of linked lives. Only Anne had a network of close friends, although most of them lived in the town where she had moved from and she no longer saw them on a regular basis; the two men had no intimate friends that they met with or could confide in. Although Mark had four children, he had lost contact with three of them and only saw his daughter infrequently, while, although Lewis had siblings, he did not describe them as being emotionally close.

Both these individuals also exemplify the point that solo living is becoming more common across many parts of the world, particularly for men, and that single men are more likely to be socially isolated than women (Klinenberg 2012, 2016; ONS 2019a; Snell 2017; Vandervoort 2000).

As far as linked, lives are concerned none of the three was living with a partner, and none had dependents. Anne's life was currently intertwined with, and enriched by, her two granddaughters and the main person in her life was her daughter. However, although Anne loved caring for her granddaughters, the fact that she needed to be available for the school run in the morning and afternoon also meant that her potential hours of employment were restricted.

\section{Agency}

Underpinning all of these themes is the concept of agency, and the level of current agency each interviewee has is affected by the past and present key people and the key events we have identified earlier. Agency is also conditional on the resources a person is able to access (economically, socially, physically, emotionally) - which in turn is linked to their personality, habits, and dispositions, which have been formed over the life course. 
Using a Life Course Perspective

This further illustrates how people's current plans and expectations are often based on past experience and future anticipations (Heinz et al. 2009).

If we consider the degree of agency each is able to express in terms of their ability to reenter the labor market, we can see that Lewis has the greatest level and therefore more capacity to do so. This is because he has the highest level of qualifications and a track record of steady employment in a professional job. However, ability and desire are two different things and his work-based pension gives him the financial capital which has allowed him to choose not to work anymore, and so he has more control of his life, at least in terms of not needing to seek paid employment. Both Anne's and Mark's agency is constrained by their poor health and their lack of skills, which have not been updated to include using new technologies. This is not to say these two have not demonstrated they have agency in other areas of their lives: Anne has made the choice to look after her granddaughters, while Mark's recent decision to leave his wife and set up a home independently, plus the fact that he has chosen to carry out voluntary work shows that he has the capability to act and exercise some control over his life.

\section{Conclusion and Discussion}

This paper has focused particularly on three people, aged 58, who had, for various reasons, left the labor market at least 8 years before the SPA. Each of these three represents the three possibilities of exiting that we wrote about in the first few lines of the paper: Anne has left employment involuntarily but wants to work; Lewis has left voluntarily and will not work; while Mark, who also left voluntarily, does not want to work and is gradually realizing that he will not work again.

As late baby boomers, their expected increasing life expectancy has made them subject to close policy attention and significant pension and employment reforms, and we maintain that finding out their reasons for not working and the barriers preventing them returning to work are particularly worthy of attention to policy makers and academics. Moreover, we also feel that it is particularly important to study those who have been, and still can be characterized as being, the working poor, most of whom have less financial capital, or resources to live on, but despite being more likely to suffer from poor health, often need to work longer to avoid an insecure 
International Journal of Ageing and Later Life

retirement. Taking the view that people's choices are based on a series of often intricate and overlapping factors is very different from the more simplistic rational choice models that assume people will need to continue work if they do not have enough money to retire. These models are used to understand the moment of exiting the labor market by studying individual's financial resources (Beehr 2014), but they tend to miss the complexity of people's lives and dispositions, including, as we have seen for example, the more seemingly subjective and irrational decisions people make based, for example, on emotional influences and ties.

In this paper, we have used a life course approach to try to explore and understand the reasons why these three individuals have made the transition to exit the labor market, and this is because, we argue, the later years of a person's life cannot be fully understood without the knowledge of the prior stages of the life course. These three are representatives of wider narratives typically found amongst this age group and from similar financial backgrounds, and we can also see how macroeconomic conditions and constraining wider structures of social class, gender, and poverty are represented, encapsulated, and demonstrated in and through these three lives. Narrative methodologies that use life course theories help us to understand more of the nuanced and interconnected factors such as how much agency people are able to express in these exits; what their expectations are, and why some people do not want to continue working, even if this means they have little money. They also show that some people prefer to live meagerly because personal contentment means more to them than material possessions, and, again arguing against rational choice theories, why some people do not reenter the job market for pecuniary reasons. When it comes to the barriers against returning to work, apart from the obvious impediment of poor health (which affected all three), there are also emotional and more ideological factors which often remain hidden in survey research. For instance, Anne was emotionally tied to looking after her granddaughters, which restricted her employment opportunities; Mark felt content working on a voluntary basis; while Lewis declared that he would not work for something he did not philosophically believe in.

We characterized the first individual we introduced as a person who was/is desperate to be employed and was looking for work; the second could/ can get by living without being employed and doesn't want to work; while the 
third had/has retired and will not work again. However, embedded within these typologies are a series of smaller themes and issues, which this in-depth enquiry has enabled researchers to reveal. Poor health (both physical and mental) is the single biggest factor that both forces people out of the labor market and prevents them returning. Poor physical health has a particular effect on people, like Mark, who have worked in manual trades, and find that their bodies have begun to break down under the sustained pressure and strain. For other people, like Luke, health concerns can cause them to lose confidence, and a degree of uncertainty begins to creep in when they think about making future plans, including possible employment opportunities. Even people like Anne, who is eager to find employment, find out that their options are compromised by health concerns, which can also reduce the hours they are able to work for. However, another factor limiting potential times and hours of employment is caring issues, for both old and, in the case of Anne, her daughter's young children. We can also speculate that this may also have a greater effect on women, who are more likely on average to take on caring responsibilities than men (ONS 2019b). Age also plays a part and even though people of Anne's age still have (at the time of fieldwork) potentially 8 years of work left before SPA, and are perhaps more likely to remain in their job than someone younger, employers can probably find, or prefer, someone younger whom, espe- cially if they are under the age of 25 (in the UK), they can pay less. People approaching 60 are also subject to the effects of age stereotypes, which are another form of age discrimination (Truxillo et al. 2018). It is also the case that, unlike in more professional work, prior experience does not count very much in relatively low-skilled jobs, such as working on supermarket checkouts, and in manual blue-collar trades, and there is also a shortage of up-to-date training provision, such as in new types of technology, and opportunities to gain new qualifications. However, in some cases, there can also be a lack of personal motivation, or even inability, to retrain or return to studying, due to low confidence and poor self-esteem. We argue that people like Mark, who undertake voluntary work as part of a civic responsibility (Haddad 2006), not only gain from the experience of a fuller working life and improved mental wellbeing, but also contribute a great deal to society - it is just that they do not get paid for it. Similarly, people who take on caring responsibilities, such as Anne, save the state 
a lot of money in child-minding fees and also make it possible for their offspring to work. Another group of people are, like Lewis, who, despite claiming they have "definitively" retired could work if they wanted to. However, there is little incentive to take a low-paid, uninteresting, and possibly high stress job when they can exist on savings they have accrued, which, in the case of Mark, is his work-based pension, even if this means that he has to live rather thriftily. Many people would be enticed back into the labor market if employment opportunities included work which people felt was making a difference to society and helping people, particularly if they had more freedom to negotiate their hours and could work part time. There are many people, like Mark, who, although they only have enough money to just about survive, are personally satisfied and not in any hurry to seek paid employment, particularly involving manual labor (McLaughlin \& Neumark 2018). Indeed, one of the key findings from the research is that many people are content to live relatively frugally due to habitual expectations accumulated over the life course, and, as long as they have a roof over their head and food on the table, will not be tempted to work for pecuniary reasons because personal contentment and general wellbeing mean more to them than material possessions or money.

To briefly summarize some of the main barriers preventing people of this age and economic background returning to the labor market, we can see that, after an individual's poor health, some of the other factors are caring responsibilities; the lack of flexibility in the market that makes it difficult for people to find part- time employment and work limited hours; a scarcity of opportunities to retrain and gain more qualifications; the economic incentives for employers to target younger workers; the age discrimination that is prevalent in society; and a shortage of interesting and intellectually stimulating work, and new alternatives to work that does not involve hard physical labor.

As far as reentering the labor market goes for the three individuals in this paper, perhaps the bottom line is that Anne is the only one of the three who is really motivated to work. If all financial streams were cut off tomorrow, all probably could work, but only in particular jobs which are more flexible and tailored to their personal needs, and very few of these are likely to exist without state planning and intervention. Indeed, the closure and subsequent privatization of the 
government-run Remploy organization (which provided employment placements for disabled people) in 2014 is but one example of an opposite trend in the UK. Although policy makers will point to the "active ageing" agenda and argue that it is of vital concern to develop and improve knowledge about the incentives that can encourage older workers to extend their working lives, it is hard to see what these could entail for these three people. Although we concur with Phillipson et al.'s (2017) assertion that there needs to be significant improvements in the quality of work, early interventions to support people with chronic health conditions, and a fundamental restructuring of the system of lifelong learning and training, an increasingly fractured society, driven by neo-liberal ideologies where the state sector is under increasing attack, makes these words look more like a utopian dream that a realistic coordinated policy option.

\section{Corresponding Author}

Jon Swain, Institute of Education, University College London, Department of Education, Practice and Society, 20 Bedford Way, London WC1H0AL, UK. Email: j.swain@ucl.ac.uk

\section{References}

Bandura, A. (2001). Social cognitive theory: an agentic perspective. Annual review of psychology 52: 1-26.

Banks, J., Emmerson, C. \& Oldfield, Z. (2005). Preparing for Retirement: The Pension Arrangements and Retirement Expectations of those Approaching State Pension Age in England. Institute for Fiscal Studies Working Paper WP05/13. https://www.ifs.org.uk/wps/wp0513.pdf (Accessed: September 8, 2020)

Banks, J. \& Smith, J. P. (2012). International comparisons in health economics: Evidence from aging studies. Annual Review of Economics 4: 57-81.

Beehr, T. A. (2014). To retire or not to retire: That is not the question. Journal of Organizational Behavior, (Special Issue) 35(8): 1093-108.

Brown, P. \& Vickerstaff, S. (2011). Health subjectivities and labor market participation: Pessimism and older workers' attitudes and narratives around retirement in the United Kingdom. Research on Aging 33(5): 529-550. 
International Journal of Ageing and Later Life

Candappa, M. (2017). Case studies. In J. Swain (ed.), Designing Research in Education: Concepts and Methodologies (pp. 173-192). London: Sage.

Carpentieri, J. \& Elliott, J. (2014). Understanding healthy aging using a qualitative approach: The value of narratives and individual biographies. In D. Kuh, R. Cooper, \& R. Hardy (eds.), A Life Course Approach to Healthy Ageing (pp. 118-129). Oxford: Oxford University Press.

Carpentieri, J. D., Goodman, A., Parsons, S., Patalay, P. \& Swain, J. (2017). Lifetime Poverty and Attitudes to Retirement among a Cohort Born in 1958. London: Centre for Longitudinal Studies. Available on https://cls. ucl.ac.uk/wp-content/uploads/2017/02/JRF-retirement-report-FINAL-August-3-20172.pdf (Accessed: June 10, 2019)

Du Prel, J-B., Schrettenbrunner, C. \& Hasselhorm, H. M. (2019). Vertical and horizontal social inequality and motivations for early retirement. Zietschrift fur Gerontologie und Geriatrie 52(1): 3-13.

DWP (Department for Work and Pensions). (2017). Fuller Working Lives: Evidence Base 2017. Available on https://www.gov.uk/government/ publications/fuller-working-lives-evidence-base-2017 (Accessed: June 21, 2019).

Ebbinghaus, B. \& Radl, J. (2015). Pushed out prematurely? Comparing objectively forced exits and subjective assessments of involuntary retirement across Europe. Research in Social Stratification and Mobility 41(9): 115-130.

Ekerdt, D. J. (2009). Frontiers of research on work and retirement. The Journals of Gerontology: Series B. 65B(1): 65-80.

Elder, G. (1994). Time, human agency, and social change: Perspectives on the life course. Social Psychology Quarterly 57(1): 4-15.

Elder, G. H. \& Giele, J. Z. (eds.) (2009). The Craft of Life Course Research. New York: Guilford Press.

Elder, G. H., Johnson, M. K. \& Crosnoe, R. (2003). The emergence and development of life course theory. In J. T. Mortimer \& M. Shanahan (eds.) Handbook of the Life Course (pp. 3-19). New York, NY: Kluwer Publishers.

Elliott, J. (2005). Using Narrative in Social Research: Qualitative and Quantitative Approaches. London: Sage.

Emirbayer, M. \& Mische A. (1998). What is agency? American Journal of Sociology 42(4): 962-1023. 
Esping-Andersen, G. (1996). Welfare States in Transition: National Adaptions in Global Economies. London: Sage.

Evans, K., Schoon, I. \& Weale, M. (2013). Can lifelong learning reshape life chances? British Journal of Educational Studies 61(1): 25-47.

Evans, K. \& Biasin, C. (2017). Exploring agency, learning and identity in women's life trajectories in United Kingdom and Italy - Exploración de la agencia, el aprendizaje y la identidad en las trayectorias de vida de las mujeres en el Reino Unido e Italia. Revista Española de Educación Comparada 29: 15-32.

Fleischmann, M., Koster, F., Dukstra, P. \& Schipppers, J. (2013). Hello pension, goodbye tension? The impact of work and institutions on older workers' labor market participation in Europe. International Journal of Ageing and Later Life 8(2): 33-67.

Formosa, M. (2014). Four decades of universities of the third age: Past, present, future. Ageing \& Society 34(1): 42-66.

Foster, L. (2018). Active ageing, pensions and retirement in the UK. Journal of Population Ageing 11(2): 117-132.

Haddad, M. (2006). Civic responsibility and patterns of voluntary participation around the world. Comparative Political Studies 39: 1220-1242.

Hallerod, B., Orestig, J. \& Stattin, M. (2013). Leaving the labour market: The impact of exit routes from employment to retirement on health and wellbeing in old age. European Journal of Ageing 10(1): 25-35.

Hamblin, K. A. H. (2010). Changes to policies for work and retirement in EU15 nations (1995-2005): An exploration of policy packages for the 50-plus cohort. International Journal of Ageing and Later Life 5(1): 13-43.

Heinz, W. H., Huinink, J. \& Weymann, A. (Eds.). (2009). The Life Course Reader: Individuals and Societies Across Time (Frankfurt, Campus). Available on https:/ / beckassets.blob.core.windows.net/ product/readingsample/493922/9783593388052_excerpt_001.pdf (Accessed: June 10, 2019)

Henretta, J. (2003). The life-course perspective on work and retirement. In R. Settersten (ed.), Invitation to the Life Course (pp. 85-106). London: Routledge.

Hofaecker, D., Hess, M. \& Koenig, S. (2019). Change of retirement transition in the political paradigm shift in Europe. Late career and retirement transitions in Germany, Austria, Sweden and Estonia. Zeitschrift fur Gerontologie und Geriatrie 52(1): 40-51. 
International Journal of Ageing and Later Life

Hovbrandt, P., Hakansson, C., Albin, M., Carlsson, G. \& Nilsson, K. (2019). Prerequisites and driving forces behind an extended working life among older workers. Scandinavian Journal of Occupational Therapy 26(3): 171-183.

Klinenberg, E. (2012). Going Solo: The Extraordinary Rise and Surprising Appeal of Living Alone. New York, NY: The Penguin Press.

Klinenberg, E. (2016). Social isolation, loneliness, and living alone: Identifying the risks for public health. American Journal of Public Health 106(5): 786-787 doi: 10.2105/ AJPH.2016.303166

Komp, K., Van Tilburg, T. \& Van Groenou, M. B. (2010). Paid work between age 60 and 70 years in Europe: A matter of socio-economic status? International Journal of Ageing and Later Life 5(1): 45-75.

Labov, W. \& Waletzky, J. (1967). Narrative analysis: Oral versions of personal experience. In J. Helm (ed.), Essays on the Verbal and Visual Arts (pp. 12-44). Seattle, WA: University of Washington Press.

Lain, D. \& Vickerstaff, S. (2015). National Report: United Kingdom. Berlin: Federal Ministry of Labour and Social Affairs (BMAS) and Federal Institute for Occupational Safety and Health. Available on www.jp-demographic.eu (Accessed: June 21, 2019).

Leinonen, T., Martikainen, P. \& Myrskylae, M. (2018). Working life and retirement expectancies at age 50 by social class: Period and cohort trends and projections for Finland. Journals of Gerontology Series B-Psychological Sciences and Social Sciences 73(2): 302-313.

Liebow, E. (1967). Tally's Corner. A Study of Negro Street Corner Men. Boston, MA: Little, Brown.

McLaughlin, J. S. \& Neumark, D. (2018). Barriers to later retirement for men: Physical challenges of work and increases in full retirement age. Research on Aging 40(3): 232-256.

Moen, P. (1996). A life course perspective on retirement, gender and well-being. Journal of Occupational Health Psychology 1(2): 131-144.

OECD (Organization for Economic Co-operation and Development). (2017). Pensions at a Glance: OECD and G20 Indicators. Available on https:/ / www.oecd-ilibrary.org/social-issues-migration-health/pensions-at-aglance-2017_pension_glance-2017-en (Accessed: June 21, 2019)

ONS (Office for National Statistics). (2019a). The Cost of Living Alone. Available on https://www.ons.gov.uk/peoplepopulationandcommunity/ 
birthsdeathsandmarriages/families/articles/thecostoflivingalone/2019-04-04 (Accessed April 20, 2020)

ONS (Office for National Statistics). (2019b). Living Longer: Caring in Later Working Life Examining the Interplay between Caring and Working in Later Life in the UK. Available on https://www.ons.gov.uk/peoplepopulationandcommunity/birthsdeathsandmarriages/ageing/articles/livinglongerhowourpopulationischangingandwhyitmatters/2019-03-15 (Accessed April 25, 2020)

Phillipson, C., Vickerstaff, S. \& Lain D. (2017). Achieving fuller working lives: Labour market and policy issues in the United Kingdom. Australian Journal of Social Issues 51(2): 187-204.

Quinn, J., Burkhauser, R. \& Myers, D. (1990). Passing the Torch: The Influence of Economic Incentives on Work and Retirement. Upjohn Press, [e-journal]. Available on: http://research.upjohn.org/up_press/81 (Accessed October 28, 2019)

Radl, J. (2013). Labour market exit and social stratification in Western Europe: The effects of social class and gender on the timing of retirement. European Sociological Review 29: 654-668. doi: 10.1093/esr/jcs04

Ragin, C. 1999. Using qualitative comparative analysis to study causal complexity. Health Services Research 34(5): 1225-1239.

Riessman, C. K. (2004). Narrative analysis. In M. S. Lewis-Beck, A. Bryman, \& T. Futing Liao (eds.), The SAGE Encyclopaedia of Social Science Research Methods (pp. 705-709). Thousand Oaks, CA: Sage.

Rudolph, K. E. \& Eaton, W. W. (2016). Previous anxiety and depression as risk factors for early labour force exit. Journal of Epidemiology and Community Health 70(4): 390-395.

Scales, J. \& Scase, R. (2000). Fit and Fifty. Swindon: Economic and Social Research Council.

Settersten, R. A. (2003). Propositions and controversies in life-course scholarship. In R. A. Settersten (ed.), Invitation to the Life Course. Toward New Understanding of Later Life (pp. 15-48). New York, NY: Baywood.

Smeaton, D., Barnes, H. \& Vegeris, S. (2017). Does retirement offer a 'window of opportunity' for healthy lifestyle change? Views from workers on the cusp of retirement. Journal of Aging and Health 29(1): 25-44.

Snell, K. D. M. (2017). The rise of living alone and loneliness in history. Social History 42(1): 2-28. doi: 10.1080/03071022.2017.1256093 
International Journal of Ageing and Later Life

Stafford, M., Cooper, R., Cadar, D., Murray, E., Richards, M., Stansfeld, S., Zaninotto, P., Head, J. \& Kuh, D. (2017). Physical and cognitive capability in mid-adulthood as determinants of retirement and extended working life in a British cohort study. Scandinavian Journal of Work Environment \& Health 43(1): 15-23.

Swain, J. (2018). A Hybrid Approach to Thematic Analysis in Qualitative Research: Using a Practical Example. Sage Research Methods Cases. London: Sage. Online ISBN: 9781526435477. doi: http://dx.doi.org/ 10.4135/9781526435477

Truxillo, D., Finkelstein, L., Pytlovany, A. \& Jenkins, J. (2018). Age discrimination at work: A review of the research and recommendation for the future. In A J. Colella \& E B. King (eds.) The Oxford Handbook of Workplace Discrimination (pp. 129-142). New York, NY: Oxford University Press.

Vandervoort, D. (2000). Social isolation and gender. Current Psychology 19(3): 229-236.

Verd, J. M. \& López, M. (2011). The rewards of a qualitative approach to life-course research. The example of the effects of social protection policies on career paths. Qualitative Social Research, 12(3), Art 15. Available on http://www.qualitative-research.net/index.php/fqs/article/ view/1753/3259 (Accessed: September 8, 2020)

Vickerstaff, S. \& Cox, J. (2005). Retirement and risk: The individualisation of retirement experiences. The Sociological Review 53(1): 77-95. 